\title{
Infection par le virus du Nil occidental en Ontario (Canada) : 2017
}

\author{
S Wijayasri ${ }^{1 *}$, MP Nelder ${ }^{1}$, CB Russell ${ }^{1}$, KO Johnson ${ }^{1}$, S Johnson², T Badiani ${ }^{1}$, D Sider ${ }^{1,3}$
}

\section{Résumé}

Contexte : Au Canada, I'incidence annuelle de l'infection par le virus du Nil occidental a fluctué au cours des 15 dernières années. L'Ontario est l'une des provinces canadiennes les plus touchées par le virus du Nil occidental. Par conséquent, la province a instauré des programmes rigoureux de surveillance des populations de moustiques et d'humains.

Objectif : Résumer les données sur l'épidémiologie de l'infection par le virus du Nil occidental en Ontario (Canada) en 2017, discuter de ces données et les comparer à celles des années antérieures.

Méthodologie : Les données sur les cas ont été obtenues du Système intégré d'information sur la santé publique de la province. Les taux d'incidence pour chaque bureau de santé publique et pour l'ensemble de la province ont été calculés en utilisant les données démographiques de la base de données SavoirSANTÉ Ontario.

Résultats : En 2017, l'incidence de l'infection par le virus du Nil occidental en Ontario était de 1,1 cas pour 100000 habitants. On a signalé 158 cas confirmés ou probables dans 27 des 36 bureaux de santé publique de la province. II s'agit du taux le plus élevé depuis 2013, mais il reste tout de même inférieur au taux signalé en 2012 (2,0 cas pour 100000 habitants). En 2017, les taux d'incidence les plus élevés ont été observés dans le comté de Windsor-Essex et dans les bureaux de santé publique de l’Est de l'Ontario. Si la saisonnalité correspond à ce qui a été observé dans les années antérieures, le nombre de cas signalés de juillet à septembre 2017 était supérieur aux prévisions. La plupart des cas ont été observés chez les personnes âgées (âge médian : 58 ans) et chez les personnes de sexe masculin (59,5\% du total provincial). Les cas les plus graves (complications neurologiques, hospitalisations, décès) ont également touché de façon disproportionnelle les hommes âgés.

Conclusion : L'infection par le virus du Nil occidental est toujours un fardeau en Ontario. L'augmentation du nombre de cas signalés en 2017 et l'augmentation du nombre de bureaux de santé publique où ces cas ont été signalés donnent à penser que le risque évolue et s'étend sur le territoire ontarien. La surveillance continue des populations de moustiques et d'humains, une meilleure connaissance des mesures de prévention, le diagnostic et le traitement précoces sont nécessaires pour atténuer les répercussions des infections par le virus du Nil occidental.
Cette œuvre est mise à la disposition selon les termes de la licence internationale Creative Commons Attribution 4.0

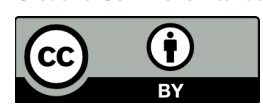

Affiliations

${ }^{1}$ Maladies entériques et zoonotiques et maladies à transmission vectorielle, Maladies transmissibles, préparation aux situations d'urgence et intervention en cas d'urgence, Santé publique Ontario, Toronto (Ontario) ${ }^{2}$ Gestion du savoir, Santé
publique Ontario, Toronto
(Ontario)

${ }^{3}$ Département d'épidémiologie clinique et de biostatistique, Université McMaster, Hamilton (Ontario)

*Correspondance: shinthuja. wijayasri@oahpp.ca

Citation proposée : Wijayasri S, Nelder MP, Russell CB, Johnson KO, Johnson S, Badiani T, Sider D. Infection par le virus du Nil occidental en Ontario (Canada) : 2017 Relevé des maladies transmissibles au Canada. 2019;45(1):34-40. https://doi.org/10.14745/ccdr.v45i01a04f

Mots-clés : Culex, moustique, surveillance, épidémiologie, santé publique, climat, virus du Nil occidental

\section{Introduction}

Le virus du Nil occidental est un agent pathogène transmis par les moustiques qui présente une préoccupation pour la santé publique au Canada. Le virus a été détecté pour la première fois en Amérique du Nord en 1999, et c'est en 2002, en Ontario, que le premier cas d'humain infecté par le virus du Nil occidental au Canada a été confirmé $(1,2)$. Depuis, le 
virus est devenu endémique au Canada, et le nombre de cas signalés annuellement à l'échelle nationale a fluctué au cours des 15 années (atteignant 2215 cas en 2007 et passant à cinq cas en 2010) (3). Depuis 2002, des cas d'infection ont été déclarés dans les dix provinces, la majorité étant survenue dans les Prairies et les provinces centrales (4). L'Ontario (qui représente environ $38,7 \%$ de la population canadienne) a déclaré des cas d'infection par le virus du Nil occidental chaque année depuis 2002. On y a d'ailleurs observé des épidémies en 2002 et en $2012(2,5,6)$.

En Ontario, les moustiques du genre Culex sont les principaux responsables de la transmission du virus du Nil occidental aux humains (7). La prolifération des moustiques et la vitesse de réplication du virus à l'intérieur ceux-ci sont fortement liés à la température et à la géographie : les conditions optimales sont les températures chaudes et les environnements urbains où les réservoirs d'eau stagnante sont répandus $(6,7)$. La majorité des populations de moustiques porteurs du virus du Nil occidental repérées en Ontario étaient dans la région du Golden Horseshoe et les zones urbaines du Sud-Ouest et du Sud-Est de l'Ontario (7). Des études ont fait état d'une forte corrélation entre le nombre de populations de moustiques porteurs du virus du Nil occidental et le nombre de cas déclarés d'humains infectés chaque année, ce qui souligne l'utilité d'un programme de surveillance des moustiques pour les détecter tôt et évaluer les risques $(6,8)$.

Bien que la majorité des cas soient asymptomatiques ou n'aient que des symptômes légers ne nécessitant pas de soins médicaux, une fraction des personnes infectées développent des problèmes graves tels qu'une maladie neuro-invasive $(9,10)$. La maladie neuro-invasive, pouvant prendre la forme d'une méningite, d'une encéphalite ou d'une paralysie flasque aiguë, est difficile à traiter et est associée à une morbidité et à une mortalité élevées ainsi qu'à des séquelles à long terme $(9,10)$. Étant donné que l'infection par le virus du Nil occidental peut mener à une maladie grave, et que seul un traitement de soutien peut être administré, les efforts de santé publique ont été axés sur la détection précoce de la maladie grâce à la surveillance des populations de moustiques et d'humains, à la promotion des mesures de prévention et à une sensibilisation accrue (9). La compréhension de l'épidémiologie du virus du Nil occidental est nécessaire pour guider ces efforts.

L'objectif du présent rapport est de résumer les données sur l'épidémiologie de l'infection par le virus du Nil occidental en Ontario (Canada) en 2017, de discuter de ces données et de les comparer à celles des années antérieures.

\section{Méthodologie}

\section{Population et définitions de cas aux fins de surveillance}

Au cours de la période de surveillance de 2017, 36 bureaux de santé publique de l'Ontario ont fourni des services de santé dans leur territoire (11). En vertu de la Loi sur la protection et la promotion de la santé, tous les bureaux de santé publique sont responsables de la gestion de cas et de la déclaration des maladies importantes sur le plan de la santé publique en Ontario (12). Les bureaux de santé publique classent les cas confirmés ou probables d'infection par le virus du Nil occidental et les déclarent en utilisant les définitions de cas aux fins de surveillance et les catégories de maladies de la province (13).

\section{Source de données}

Pour déclarer les cas d'infection par le virus du Nil occidental au gouvernement provincial, les bureaux de santé publique utilisent le Système intégré d'information sur la santé publique de I'Ontario (SIISP) en ligne. Les déclarations soumises par les bureaux de santé publique comprennent des renseignements démographiques ainsi que de l'information sur l'exposition, les symptômes, les hospitalisations et les décès. Les détails relatifs aux cas confirmés ou probables d'infection par le virus du Nil occidental survenus de 2005 à 2017 ont été extraits du SIISP. La date de l'épisode est une approximation du début de l'infection et est établie en fonction de la première date connue selon la chronologie suivante : date d'apparition des symptômes, date de prélèvement de l'échantillon, date de réception des résultats de laboratoire et date de la déclaration.

\section{Analyses}

Les analyses descriptives ont été réalisées en utilisant les logiciels SAS 9.3 et Microsoft Excel 2010. Les données de cas tirées du SIISP ont servi à décrire les tendances géographiques, la saisonnalité, les distributions en fonction de l'âge et du sexe et les résultats cliniques des cas d'infection par le virus du Nil occidental déclarés en Ontario en 2017. Afin d'éliminer le biais associé à l'épidémie de 2012, cette année a été exclue du calcul des moyennes historiques. Des moyennes historiques sur quatre ans (2013-2016) ont servi de comparateurs aux données de 2017 (6). Les taux d'incidence provinciaux (2005-2016) et les taux d'incidence par bureau de santé publique (2017) ont été calculés pour 100000 habitants par année à partir des estimations démographiques de la province et des bureaux de santé publique (2005-2016) et des projections (2017) obtenues de Statistique Canada par l'intermédiaire de SavoirSANTÉ Ontario. Compte tenu des incertitudes liées au lieu de l'exposition, les cas de patients affirmant avoir voyagé à l'extérieur de la province pendant la période d'incubation du virus n'ont pas été exclus des analyses. Le logiciel ArcGISMC v10.3 d'ESRI (ESRI, Redlands, Californie, États-Unis) a servi à cartographier les taux d'incidence de l'infection par le virus du Nil occidental déclarés par les 
bureaux de santé publique en 2017. Les taux ont été regroupés en catégories en utilisant une méthode de classification manuelle.

\section{Énoncé des valeurs éthiques}

Le présent manuscrit fait état des activités de surveillance systématique et non de la recherche. Par conséquent, l'approbation du comité d'éthique de la recherche n'était pas requise. Santé publique Ontario fournit les données sur demande; voir https://www.publichealthontario.ca/fr/Quisommes-nous/Pages/privacy.aspx.

\section{Résultats}

\section{Généralités}

En 2017, 158 cas confirmés ou probables d'infection par le virus du Nil occidental ont été déclarés en Ontario, un nombre bien supérieur à la moyenne historique sur quatre ans de 40 cas par année. II s'agit du deuxième pic en termes de nombre de cas déclarés en une seule année depuis 2005. Le nombre de cas signalés augmente chaque année depuis 2014 (voir la figure 1). Le taux d'incidence de l'infection par le virus du Nil occidental en Ontario en 2017 était de 1,1 cas pour 100000 habitants, taux qui a presque triplé par rapport à $2016(0,4$ cas pour 100000 habitants), mais qui est inférieur à celui de 2012 (2,0 cas pour 100000 habitants).

Figure 1 : Nombre de cas confirmés ou probables d'infection par le virus du Nil occidental et incidence (pour 100000 habitants), par année, en Ontario (Canada), 2005-2017

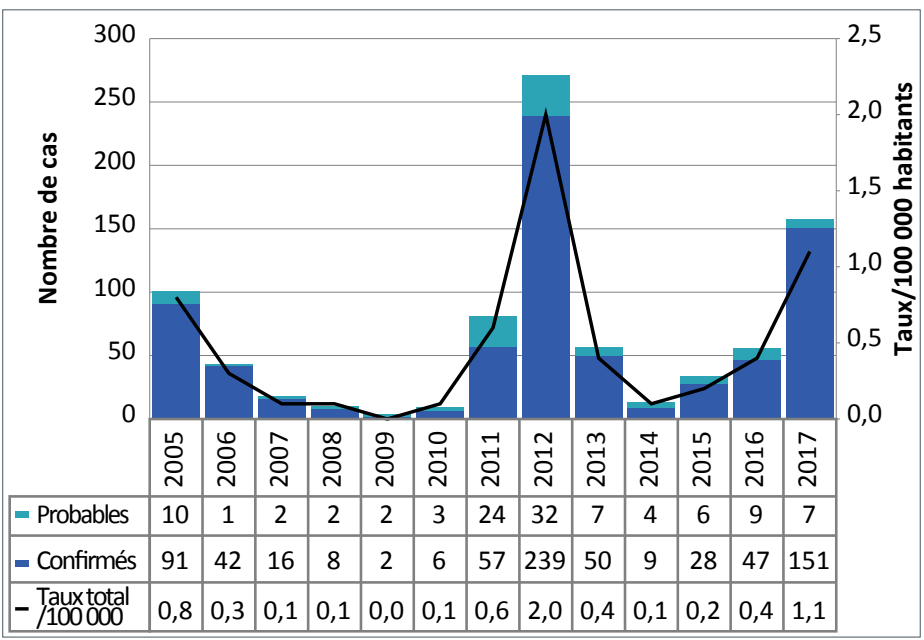

\section{Distribution géographique}

Vingt-sept bureaux de santé publique ont déclaré des cas d'infection par le virus du Nil occidental en 2017. Ce nombre est plus élevé que celui des quatre années précédentes (2013-2016), durant lesquelles de 13 à 15 bureaux de santé publique ont signalé des cas annuellement. Sur le nombre total de cas déclarés en Ontario en 2017, la majorité des cas ont été signalés à Toronto $(28 / 158,17,7 \%)$, puis à Ottawa $(20 / 158,12,7 \%)$ et dans le comté de Windsor-Essex (20/158, 12,7 \%). Les hausses observées à Ottawa (7,5 fois sa moyenne historique sur quatre ans) et dans le comté de Windsor-Essex (5,7 fois sa moyenne historique sur quatre ans) sont particulièrement importantes (voir le tableau 1).

Tableau 1 : Nombre de cas confirmés ou probables d'infection par le virus du Nil occidental déclarés en 2017, comparativement aux moyennes historiques sur quatre ans (de 2013 à 2016), par bureau de santé publique $^{a}$, en Ontario (Canada)

\begin{tabular}{|c|c|c|c|}
\hline \multirow[t]{2}{*}{ Bureau de santé publique } & \multicolumn{2}{|c|}{2017} & \multirow{2}{*}{$\begin{array}{c}2013-2016 \\
\text { Moyenne } \\
\text { sur quatre } \\
\text { ans }\end{array}$} \\
\hline & $\mathrm{n}$ & $\%$ & \\
\hline Ville de Toronto & 28 & 17,7 & 12,5 \\
\hline Ville d'Ottawa & 20 & 12,7 & 2,7 \\
\hline Comté de Windsor-Essex & 20 & 12,7 & 3,5 \\
\hline Région de York & 12 & 7,6 & 1,5 \\
\hline Région de Peel & 10 & 6,3 & 4,3 \\
\hline Région de Niagara & 8 & 5,1 & 5,7 \\
\hline District de Simcoe Muskoka & 7 & 4,4 & 1,3 \\
\hline Ville de Hamilton & 6 & 3,8 & 3,7 \\
\hline Région de Halton & 6 & 3,8 & 1,5 \\
\hline District de Leeds, Grenville et Lanark & 6 & 3,8 & 0,0 \\
\hline Est de l'Ontario & 5 & 3,2 & 1,0 \\
\hline Grey Bruce & 4 & 2,5 & 0,0 \\
\hline Région de Durham & 3 & 1,9 & 0,0 \\
\hline Haliburton, Kawartha, Pine Ridge & 3 & 1,9 & 0,0 \\
\hline Comté et cité de Peterborough & 3 & 1,9 & 0,0 \\
\hline Région de Waterloo & 3 & 1,9 & 0,0 \\
\hline $\begin{array}{l}\text { Kingston, Frontenac, Lennox et } \\
\text { Addington }\end{array}$ & 2 & 1,3 & 0,0 \\
\hline Sudbury et district & 2 & 1,3 & 1,0 \\
\hline Wellington-Dufferin-Guelph & 2 & 1,3 & 1,0 \\
\hline Haldimand-Norfolk & 1 & 0,6 & 0,0 \\
\hline Comtés de Hastings et Prince Edward & 1 & 0,6 & 0,0 \\
\hline Comté de Lambton & 1 & 0,6 & 1,0 \\
\hline Middlesex-London & 1 & 0,6 & 2,0 \\
\hline Comté d'Oxford & 1 & 0,6 & 1,0 \\
\hline District de Perth & 1 & 0,6 & 0,0 \\
\hline Comté et district de Renfrew & 1 & 0,6 & 1,0 \\
\hline Timiskaming & 1 & 0,6 & 0,0 \\
\hline Total (Ontario) & 158 & 100,0 & 40,0 \\
\hline
\end{tabular}

Abréviation : n, nombre

Le bureau de santé publique indiqué correspond au lieu de résidence de la personne touchée au début de l'infection, et pas nécessairement au lieu d'exposition. On ne peut pas associer le lieu d'acquisition à un bureau de santé publique. Seuls les bureaux de santé publique ayant déclaré des cas en 2017 apparaissent dans ce tableau $(n=27)$

b Le pourcentage $(\%)$ correspond à la proportion par rapport au nombre total de cas déclarés en Ontario en $2017(n=158)$

C'est dans le comté de Windsor-Essex que le taux d'incidence le plus élevé a été observé en Ontario en 2017 (4,9 cas pour 
100000 habitants). Des taux d'incidence élevés ont également été observés dans les régions de santé publique de l'Est de I'Ontario où la population est peu dense (voir la figure 2), notamment dans le district de Leeds, Grenville et Lanark (3,5 cas pour 100000 habitants), le Timiskaming (3,0 cas pour 100000 habitants) et l'Est de I'Ontario (2,4 cas pour 100000 habitants). Parmi les cas d'exposition déclarés en $2017,9,2 \%$ (13 sur 141) des personnes ont indiqué qu'elles avaient voyagé à l'extérieur de la province pendant la période d'incubation.

Figure 2 : Incidence de l'infection par le virus du Nil occidental (pour 100000 habitants) en 2017, par bureau de santé publique ${ }^{a}$, en Ontario (Canada)

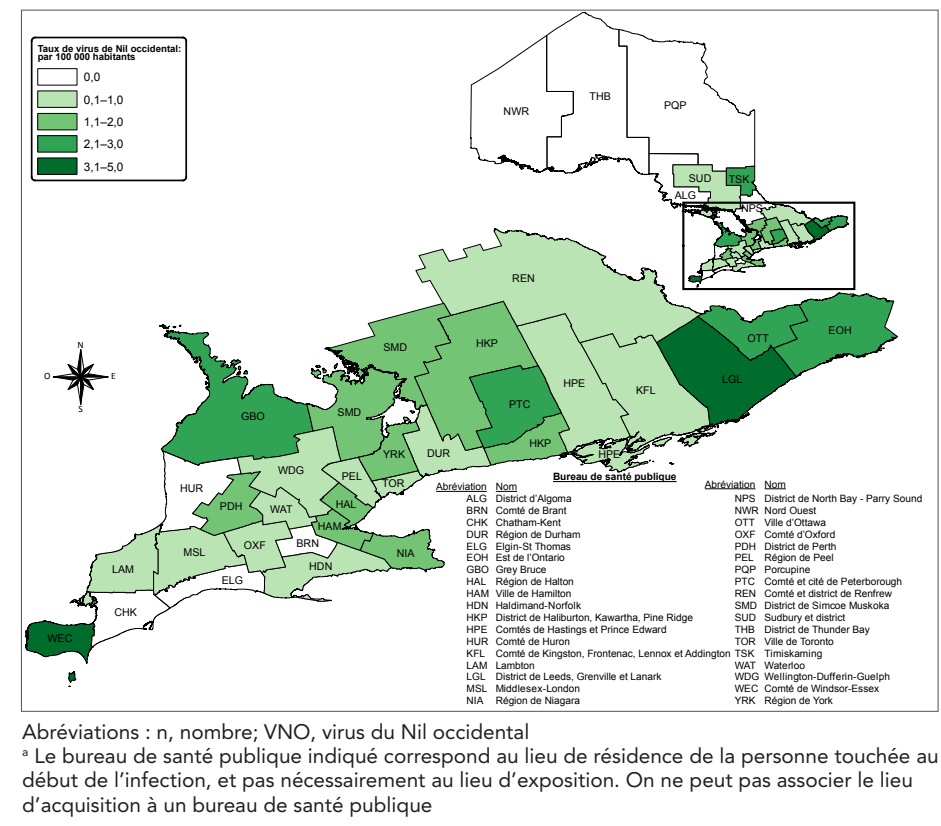

\section{Saisonnalité}

La majorité des cas sont survenus de juillet à septembre 2017; la proportion la plus élevée $(57,6 \%$ ) a été observée en août (voir la figure 3). La distribution saisonnière des cas déclarés en 2017 est comparable à celle des années antérieures, avec un pic en août. Toutefois, le nombre de cas par mois était plus de quatre fois plus élevé que la moyenne de juillet (19 cas observés contre 4 cas prévus) et d'août (91 cas observés contre 17 cas prévus) des quatre années précédentes.

\section{Distribution selon l'âge et le sexe}

L'âge des cas d'infection par le virus du Nil occidental observés en 2017 allait de 5 à 89 ans. Les groupes âgés (âge médian : 58 ans) et les personnes de sexe masculin (59,5\% du total provincial) étaient les plus touchés (voir la figure 4). Plus précisément, 50,6\% des cas déclarés en 2017 étaient âgés de 50 à 69 ans et $51,3 \%$ des cas étaient des hommes de plus de 45 ans. De manière générale, la distribution en fonction de l'âge en 2017 correspond aux tendances observées au cours des quatre années antérieures. Cependant, le rapport entre les personnes de sexe masculin/féminin était plus élevé dans les
Figure 3 : Nombre de cas confirmés ou probables d'infection par le virus du Nil occidental déclarés en 2017, comparativement aux moyennes historiques sur quatre ans (de 2013 à 2016), par mois d'épisode, en Ontario (Canada)

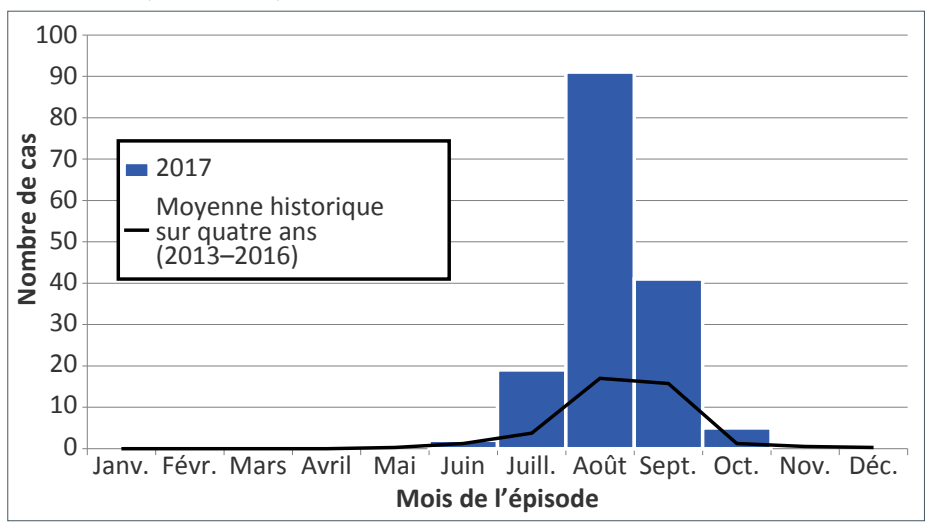

Figure 4 : Nombre de cas confirmés ou probables d'infection par le virus du Nil occidental déclarés en 2017, comparativement aux moyennes historiques sur quatre ans (de 2013 à 2016), par groupe d'âge ${ }^{a}$ et sexe, en Ontario (Canada)

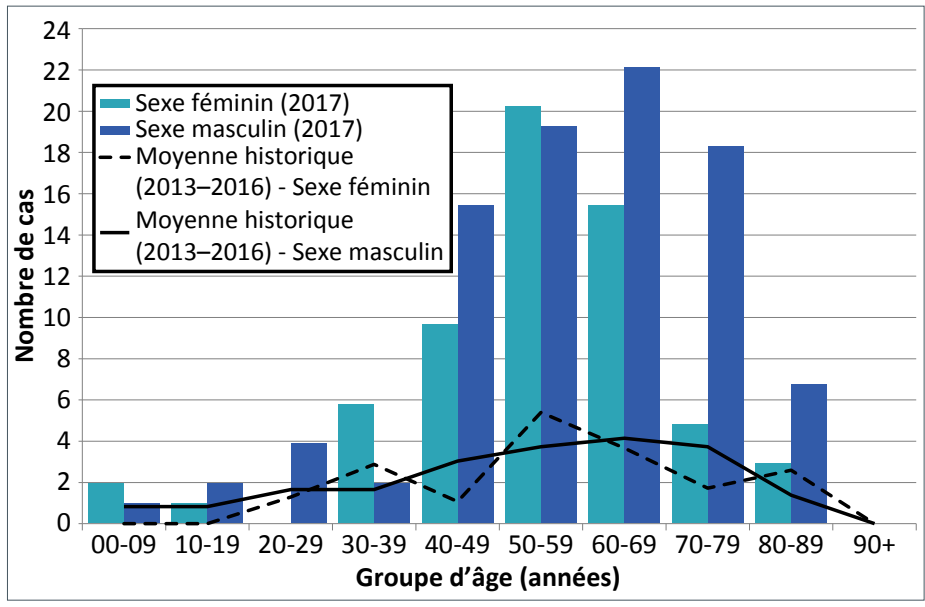

Le groupe d'âge correspond au groupe d'âge (en années) auquel appartenait la personne touchée pendant l'infection

groupes plus âgés, en particulier chez les 40 à 49 ans ( 1,6 fois), les 60 à 69 ans ( 1,4 fois) les 70 à 79 ans ( 3,8 fois) et les 80 à 89 ans (2,3 fois).

\section{Résultats cliniques}

Des 158 cas déclarés en 2017, 38,6 \% (61/158) ont eu des complications neurologiques; $37,3 \%$ (59/158) ont présenté un syndrome non neurologique et 2,5\% (4/158) n'ont eu aucun symptôme. Le tableau clinique n'était pas précisé dans $21,5 \%$ (34/158) des cas (voir le tableau 2). L'hospitalisation était indiquée dans 38,6\% (61/158) des cas déclarés en 2017, dont $72,1 \%$ (44/61) en raison de complications neurologiques et $14,8 \%(9 / 61)$ en raison d'un syndrome non neurologique. Le tableau clinique n'était pas précisé dans 13,1\% (8/61) des hospitalisations. L'âge médian des cas hospitalisés était de 
Tableau 2 : Nombre et proportion de cas confirmés ou probables d'infection par le virus du Nil occidental, selon la gravité de l'infection et l'année, en Ontario (Canada), 2013-2017

\begin{tabular}{|c|c|c|c|c|c|c|c|c|c|c|}
\hline \multirow[t]{2}{*}{ Gravité de l'infection } & \multicolumn{2}{|c|}{2013} & \multicolumn{2}{|c|}{2014} & \multicolumn{2}{|c|}{2015} & \multicolumn{2}{|c|}{2016} & \multicolumn{2}{|c|}{2017} \\
\hline & $\mathbf{n}$ & $\%$ & $\mathbf{n}$ & $\%$ & $\mathbf{n}$ & $\%$ & $\mathbf{n}$ & $\%$ & $n$ & $\%$ \\
\hline Tableau clinique (tous les cas) & 57 & 100 & 13 & 100 & 34 & 100 & 56 & 100 & 158 & 100 \\
\hline Asymptomatique & 3 & 5,3 & 1 & 7,7 & 1 & 2,9 & 4 & 7,1 & 4 & 2,5 \\
\hline Syndrome non neurologique & 22 & 38,6 & 3 & 23,1 & 12 & 35,3 & 13 & 23,2 & 59 & 37,3 \\
\hline Complications neurologiques & 17 & 29,8 & 6 & 46,2 & 14 & 41,2 & 32 & 57,1 & 61 & 38,6 \\
\hline Tableau clinique non précisé & 15 & 26,3 & 3 & 23,1 & 7 & 20,6 & 7 & 12,5 & 34 & 21,5 \\
\hline Hospitalisationa & 19 & 33,3 & 4 & 30,8 & 13 & 38,2 & 27 & 48,2 & 61 & 38,6 \\
\hline Décès ${ }^{b}$ & 2 & 3,5 & 0 & 0,0 & 0 & 0,0 & 6 & 10,7 & 9 & 5,7 \\
\hline
\end{tabular}

Abréviation : n, nombre

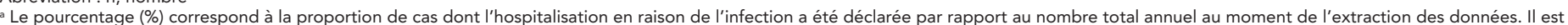

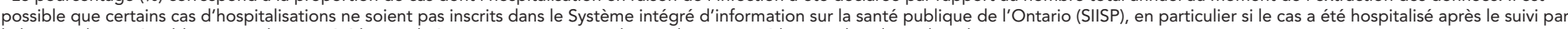
le bureau de santé publique ou si le cas a été hospitalisé pour une autre raison lorsqu'il a contracté le virus du Nil occidental

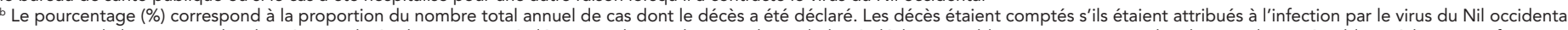

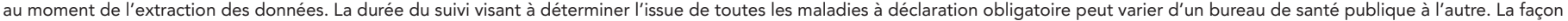
d'enregistrer les types et les causes de décès dans le SIISP peut également varier

65 ans (tranche d'âge de 5 à 80 ans), et 68,9\% (42/61) des cas étaient de sexe masculin. Des 158 cas d'infection par le virus du Nil occidental déclarés en 2017, 9 sont décédés (taux de létalité : $5,7 \%)$. L'infection par le virus du Nil occidental a été citée comme étant la cause sous-jacente du décès ou ayant contribué au décès dans six de ces cas $(66,7 \%)$. L'âge médian des neuf cas de décès était de 79 ans (tranche de 54 à 89 ans), et six d'entre eux $(66,7 \%)$ étaient des hommes. À titre de comparaison, le nombre de décès déclarés de 2013 à 2016 variait de zéro à six décès par année.

\section{Discussion}

Le nombre de cas d'infection par le virus du Nil occidental déclaré en Ontario était plus élevé en 2017 que celui des quatre années antérieures. Cette tendance correspond aux observations relatives aux populations de moustiques porteurs du virus du Nil occidental répertoriées en Ontario (14). La saisonnalité des cas d'infection par le virus du Nil occidental déclarés en 2017 concordait aussi avec les observations faites lors des saisons antérieures aux États-Unis et en Ontario $(2,15)$. Cependant, si la distribution des cas d'infection par le virus du Nil occidental dans les zones urbaines de l'Ontario (Toronto, Ottawa, comté de Windsor-Essex, régions de York et de Peel) cadre avec la surveillance des populations de moustiques menée dans la province, des augmentations ont également été observées dans des régions de santé publique rurales de l'Est de l'Ontario où la population est peu dense $(6,16)$. La distribution en fonction de l'âge et du sexe des cas déclarés en 2017, était aussi comparable à celle des années précédentes, les groupes plus âgés et les personnes de sexe masculin étant touchés de façon disproportionnelle. De plus, la majorité des cas ayant une issue clinique grave (complications neurologiques, hospitalisations ou décès) étaient plus âgés et principalement de sexe masculin, ce qui concorde avec les observations antérieures, à savoir que le vieillissement et le sexe masculin sont des facteurs de risque d'issues graves et de séquelles à long terme de l'infection par le virus du Nil occidental $(15,17)$.

\section{Conséquences et prochaines étapes}

Si la cause de l'augmentation ne peut être cernée d'emblée, certains facteurs contributifs peuvent être pointés du doigt. L'Ontario a connu un hiver 2016-2017 relativement doux (températures au-dessus des moyennes historiques) suivi d'un printemps normal et d'un été hâtif (18). Les températures douces de l'hiver ont permis à un nombre accru de moustiques Culex de survivre, ce qui signifie que beaucoup plus de moustiques porteurs du virus du Nil occidental ont pu commencer le cycle de transmission du virus au printemps et à l'été $(19,20)$. Ce raisonnement permet également d'expliquer pourquoi l'augmentation de 2017 était supérieure aux attentes, sans atteindre les niveaux de 2012, étant donné que les températures moyennes au printemps et en été n'étaient pas assez élevées pour accélérer la prolifération des moustiques et l'amplification du virus $(20,21)$.

Les prochaines étapes touchent de plusieurs aspects de la santé publique. La période de surveillance de 2017 souligne l'importance du rôle que jouent les données de surveillance robustes et exhaustives dans les efforts de prévention et de lutte contre le virus du Nil occidental. Étant donné que la température est un facteur déterminant pour la prolifération des moustiques et l'amplification du virus, la surveillance de la température, parallèlement à la surveillance des populations de moustiques et d'humains, est essentielle à la détection précoce et à l'évaluation de la fluctuation du risque de transmission du virus du Nil occidental. Une surveillance des populations de moustiques qui s'étend sur plusieurs années est nécessaire afin de déterminer si les niveaux de risque évoluent, en particulier 
dans l'Est de l'Ontario, mais aussi ailleurs dans la province. De telles données de surveillance sont essentielles pour orienter les mesures de santé publique ciblées, telles que l'augmentation de la sensibilisation et des connaissances relatives aux mesures préventives et au diagnostic précoce, particulièrement auprès des groupes plus âgés et des personnes à risque d'atteinte grave.

\section{Limites}

Comme c'est le cas avec la plupart des systèmes de surveillance passive, l'incidence réelle de l'infection est sous-représentée. En effet, divers facteurs interfèrent avec la déclaration des cas, notamment la sensibilisation, les comportements liés à I'obtention des soins de santé et les variations en matière d'analyses cliniques. Par conséquent, l'incidence de l'infection par le virus du Nil occidental est probablement sous-estimée et les données contiennent possiblement une proportion exagérée de cas ayant des symptômes cliniques ou des issues graves. Étant donné que les cas d'infection par le virus du Nil occidental sont en majorité asymptomatiques ou associés à des symptômes légers et que ces cas échappent probablement aux systèmes de surveillance, il est particulièrement difficile d'estimer le fardeau provincial réel des infections par le virus du Nil occidental. L'Agence de la santé publique du Canada estime que de 18000 à 27000 cas d'infection par le virus du Nil occidental n'ont pas été déclarés ni diagnostiqués de 2002 à 2013 au pays (4). Par ailleurs, les distributions géographiques présentées dans ce rapport sont fondées sur la région de santé publique de résidence de la personne touchée pendant l'infection. Elles ne reflètent donc pas nécessairement le lieu d'exposition au virus. Les lieux d'exposition inscrits au SIISP (y compris en cas d'exposition lors d'un déplacement) ne suffisent pas à déterminer à quel endroit une personne a contracté le virus.

\section{Conclusion}

Le nombre de cas d'infection par le virus du Nil occidental déclarés en Ontario a augmenté dans les dernières années. Bien qu'il soit difficile de prévoir l'ampleur virus du Nil occidental et ses répercussions en raison des variations relatives à la biologie du vecteur du virus, au climat et à l'activité humaine, on peut s'attendre à une hausse du nombre de cas d'infection par le virus du Nil occidental en Ontario et dans l'ensemble du pays à mesure que les températures augmentent. Grâce à une surveillance continue et renforcée des populations de moustiques et d'humains, à une sensibilisation accrue aux mesures de prévention et à des soins cliniques axés sur le diagnostic et le traitement précoces, on peut atténuer l'impact de l'infection par le virus du Nil occidental au Canada.

\section{Déclaration des auteurs}

S. W. - Conceptualisation, méthodologie, analyse, interprétation, rédaction de la première ébauche, examen et révision
M. P. N., C. B. R. - Conceptualisation, méthodologie, analyse, interprétation, rédaction de la première ébauche (sections), examen et révision

K. O. J., S. J., T. B., D .S . - Méthodologie, analyse, interprétation, examen et révision

\section{Conflit d'intérêts}

Aucun

\section{Remerciements}

Les auteurs remercient les bureaux de santé publique pour leur engagement continu dans la lutte contre le virus du Nil occidental par la prise en charge, la surveillance et la déclaration des cas.

\section{Financement}

Ce travail a été réalisé avec l'aide de Santé publique Ontario.

\section{Références}

1. Murray KO, Walker C, Gould E. The virology, epidemiology, and clinical impact of West Nile virus: a decade of advancements in research since its introduction into the Western Hemisphere. Epidemiol Infect 2011 Jun;139(6):80717. DOI PubMed

2. Public Health Ontario. Infectious disease in focus: West Nile virus. Monthly infectious diseases surveillance report 2012 Dec;1(13):1-14. https://www.publichealthontario.ca/ en/DataAndAnalytics/Documents/2012_December_PHO_ Monthly_Report.pdf

3. Surveillance du virus du Nil occidental. Ottawa (ON): Agence de la santé publique du Canada. https://www.canada.ca/ $\mathrm{fr} /$ sante-publique/services/maladies/virus-nil-occidental/ surveillance-virus-nil-occidental.html

4. Zheng H, Drebot MA, Coulthart MB. Le virus du Nil occidental au Canada : un virus en évolution permanente, mais présent pour de bon. Relevé des maladies transmissibles au Canada 2014;40(10):199-204. DOI

5. Coup d'œil sur le Canada 2018 : Population. Ottawa (ON): Statistique Canada. https://www150.statcan.gc.ca/n1/ pub/12-581-x/2018000/pop-fra.htm

6. Giordano BV, Kaur S, Hunter FF. West Nile virus in Ontario, Canada: A twelve-year analysis of human case prevalence, mosquito surveillance, and climate data. PLoS One 2017 Aug;12(8):e0183568. DOl PubMed

7. Public Health Ontario. Vector-borne diseases: 2016 Summary Report. Toronto (ON): Ontario Agency for Health Protection and Promotion; 2017 Jun. https://www.publichealthontario. ca/en/eRepository/Vector-Borne_Diseases_Summary_ Report_2016.pdf 
8. Kilpatrick AM, Pape WJ. Predicting human West Nile virus infections with mosquito surveillance data. Am J Epidemiol 2013 Sep;178(5):829-35. DOI PubMed

9. Gray TJ, Webb CE. A review of the epidemiological and clinical aspects of West Nile virus. Int J Gen Med 2014 Apr;7:193-203. DOI PubMed

10. Patel H, Sander B, Nelder MP. Long-term sequelae of West Nile virus-related illness: a systematic review. Lancet Infect Dis 2015 Aug;15(8):951-9. DOl PubMed

11. Ontario Ministère de la Santé et des soins de longue durée. Services de santé dans votre collectivité : Emplacements des bureaux de santé. Toronto (ON): Gouvernement de l'Ontario. http://www.health.gov.on.ca/fr/common/system/services/ phu/locations.aspx

12. Gouvernement de l'Ontario. protection et la promotion de la santé (Loi sur la), L.R.O. 1990, chap. H.7. R.R.O 1990, Règlement 569: Rapports. 2018 du 1er mai. https://www. ontario.ca/fr/lois/loi/90h07

13. Ministry of Health and Long-Term Care. Infectious Disease Protocol: Appendix B: Provincial Case Definitions for reportable diseases: Disease: West Nile virus illness. Toronto (ON): Government of Ontario; 2017 Mar. http://www.health. gov.on.ca/en/pro/programs/publichealth/oph_standards/ docs/wnv_cd.pdf

14. West Nile virus surveillance. Surveillance week 43 (Oct 21-Oct 27, 2018). Provincial trends. Toronto (ON): Public Health Ontario. https://www.publichealthontario.ca/en/ DataAndAnalytics/Pages/WNV.aspx
15. Lindsey NP, Staples JE, Lehman JA, Fischer M; Centers for Disease Control and Prevention (CDC). Surveillance for human West Nile virus disease - United States, 1999-2008. MMWR Surveill Summ 2010 Apr;59(2 SS02):1-17. PubMed

16. Beroll H, Berke O, Wilson J, Barker IK. Investigating the spatial risk distribution of West Nile virus disease in birds and humans in southern Ontario from 2002 to 2005. Popul Health Metr 2007 May;5(3):1-16. DOI PubMed

17. Lim SM, Koraka P, Osterhaus AD, Martina BE. West Nile virus: immunity and pathogenesis. Viruses 2011 Jun;3(6):811-28. DOI PubMed

18. Bulletins des tendances et variations climatiques. Ottawa $(\mathrm{ON})$ : Environnement et ressources naturelles. https:// www.canada.ca/fr/environnement-changement-climatique/ services/changements-climatiques/recherche-donnees/ tendances-variabilite-climatiques/tendances-variations.htm

19. Dohm DJ, Turell MJ. Effect of incubation at overwintering temperatures on the replication of West Nile Virus in New York Culex pipiens (Diptera: culicidae). J Med Entomol 2001 May;38(3):462-4. DOl PubMed

20. Reisen WK, Thiemann T, Barker CM, Lu H, Carroll B, Fang $Y$, Lothrop HD. Effects of warm winter temperature on the abundance and gonotrophic activity of Culex (Diptera: Culicidae) in California. J Med Entomol 2010 Mar;47(2):230_ 7. DOI PubMed

21. Dohm DJ, O'Guinn ML, Turell MJ. Effect of environmental temperature on the ability of Culex pipiens (Diptera: Culicidae) to transmit West Nile virus. J Med Entomol 2002 Jan;39(1):221-5. DOI PubMed 